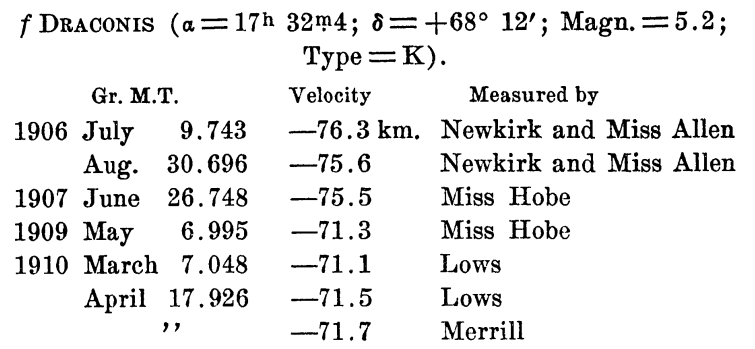

The variable velocity was discovered by Miss Hobe from the fourth plate.

$$
\begin{aligned}
& \text { A SAGITTARII }\left(\alpha=19^{\mathrm{h}} 52 \mathrm{~m} 8 ; \delta=-26^{\circ} 28^{\prime} ; \text { Magn. }=5.0\right. \text {; } \\
& \text { Type }=\text { G5). } \\
& \text { Gr. M.T. Velocity Measured by Remarks } \\
& 1908 \text { July } 15.873-49.6 \mathrm{~km} \text {. Miss Allen } \\
& \text { July } 23.839-48.1 \quad \text { Miss Allen } \\
& \text { Sept. } 4.623-36.5 \quad \text { Curtis 2-prism } \\
& \text { ", } \quad-36.1 \quad \text { Olivier } \\
& \text { Sept. } 8.617-39.0 \quad \text { Curtis } 2 \text { 2-prism } \\
& 1909 \text { June } 22.840-45.0 \quad \text { Mrs. Moore } \\
& \text { Aug. } 9.730-48.0 \quad \text { Mrs. Moore }
\end{aligned}
$$

The variation in velocity was observed by $\mathrm{Mr}$. Campbell, on comparing the third result, obtained by Curtis and Paddock in Chile, with the first and second, obtained at Mt. Hamilton. The last four plates were secured by the D. O. Mills Expedition.

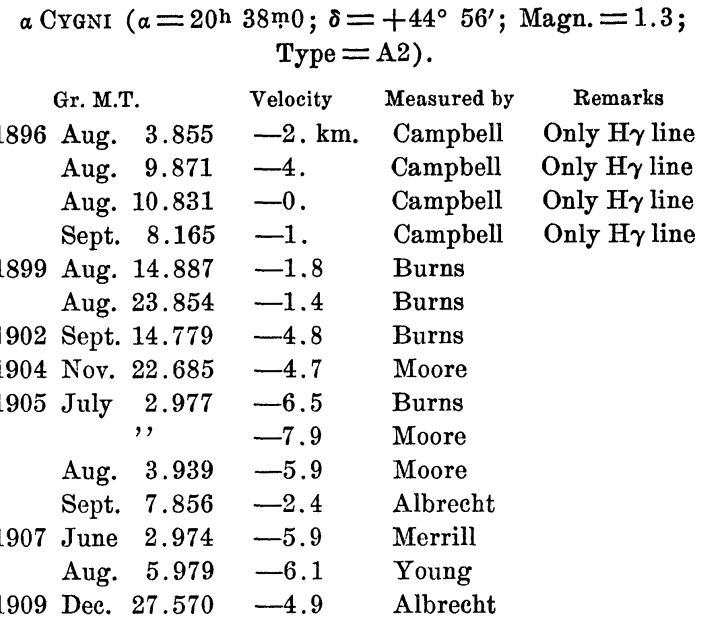

It is not intended to use the first four results in definitive computations. The variable velocity was determined by Campbell and Albrecht. Independent discovery was made by Lee, as published in the Astrophysical Journal, 31, 177, 1910.

\section{W. W. Campbell.}

June 10, 1910.

\title{
THE SPECTRA OF SOME WOLF-RAYET STARS.
}

In the summer of 1908, during the course of some work on radial velocities with the 36 -inch telescope and single-prism spectrograph of the Lick Observatory, it was found convenient to photograph the spectra of a few of the brighter stars of the WolfRayet type. Ten measurable plates, including seven different stars, were secured. During my stay at Mount Hamilton time was found for the measurement of only three of these plates, - those of Campbell's "Hydrogen Envelope" star, B.D. +30:3639. The others were measured during a visit at Flagstaff, Arizona, in August, 1909, with a measuring engine kindly made available by the Lowell Observatory.

\begin{tabular}{|c|c|c|c|}
\hline \multicolumn{4}{|c|}{ P. S. T. of Mid-exp. } \\
\hline 08 July & $4^{\mathrm{d}}$ & $15^{\mathrm{h}}$ & 18 \\
\hline July & 7 & 14 & 51 \\
\hline July 2 & 21 & 15 & 2 \\
\hline July & 25 & 14 & 36 \\
\hline Aug. & 1 & 13 & 32 \\
\hline Aug. & 8 & 14 & 14 \\
\hline Aug. 1 & 11 & 13 & 24 \\
\hline Aug. & 15 & 11 & 43 \\
\hline Aug. & 15 & 13 & 3 \\
\hline Sept. & 3 & 11 & \\
\hline
\end{tabular}

The spectra of these and many other stars of the

\begin{tabular}{|c|c|c|c|}
\hline $\begin{array}{l}\text { Duration } \\
\text { of } \\
\text { Exposure }\end{array}$ & $\begin{array}{c}\text { Slit } \\
\text { Width } \\
\text { mm. }\end{array}$ & $\begin{array}{c}\text { Comp'n } \\
\text { Spec. }\end{array}$ & Kind of plate \\
\hline $90^{\mathrm{m}}$ & .063 & $\mathrm{Fe}$ & Lumiere $\Sigma$ \\
\hline 140 & .058 & $\mathrm{H}$ & Lumiere $\Sigma$ \\
\hline 146 & .063 & $\mathrm{H}$ & Lumiere $\Sigma$ \\
\hline 60 & .038 & $\mathrm{Fe}$ & Lumiere $\Sigma$ \\
\hline 95 & .040 & $\mathrm{H}$ & Cramer Iso \\
\hline 120 & .040 & $\mathrm{Fe}$ & Seed 27 \\
\hline 140 & .040 & $\mathrm{Fe}$ & Seed 27 \\
\hline 74 & .040 & $\mathrm{Fe}$ & Lumiere $\Sigma$ \\
\hline 134 & .040 & $\mathrm{Fe}$ & Lumiere $\mathbf{\Sigma}$ \\
\hline 75 & .038 & Fe & Seed 27 \\
\hline
\end{tabular}
same type were investigated several years ago by Director Campbell, ${ }^{1}$ but since then a photographic "correcting lens" has been placed in front of the slit, and a spectrograph greatly improved for photographic observation, particularly in regard to rigidity and temperature control, has been provided.

The photographs are as follows:

\begin{tabular}{lrc} 
& \multicolumn{2}{c}{ B.D. } \\
12C & $+30^{\circ}$ & 3639 \\
17B & 30 & 3639 \\
27C & 30 & 3639 \\
32A & 35 & 3953 \\
33A & 36 & 5956 \\
$39 \mathrm{H}$ & 36 & 3956 \\
44B & 35 & 4013 \\
$47 \mathrm{C}$ & 37 & 3821 \\
$48 \mathrm{~B}$ & 36 & 3987 \\
56A & +43 & 3571
\end{tabular}

1 Astronomy and Astrophysics, 13, 448, 1894. 
Inspection and measurement of the plates resulted in collecting the following data:

$$
\text { B.D. }+30: 3639 \text {. }
$$

Plate 12C.-Bright and narrow $\mathrm{H} \beta, \mathrm{H} \gamma, \mathrm{H} \delta, \mathrm{H}_{\epsilon}$; bright and narrow line at $\lambda 4068.41$; bright band $7.3 \mathrm{~A}$. U. wide at $\lambda 4651.80$; faint continuous spectrum on either side of band, brighter toward red.

Plate 17B.-Measurements on this plate give $\lambda 4651.5$ and $\lambda 4068.30$ for band and unknown line.

Plate 27C.-Line at $\lambda 4068.58$, band at $\lambda 4651.30$.

The definite character of the hydrogen lines and the stability of the spectrograph enabled the star's radial velocity to be determined with considerable accuracy. For this purpose the lines $\mathrm{H}_{\gamma}, \mathrm{H} \delta$, and $\mathrm{H}_{\epsilon}$ were used. The results were:

$$
\begin{array}{cl}
\text { Date } & \text { Velocity relative to Sun } \\
\text { 1908 July } 4 & -25.4 \mathrm{~km} \text {. per second } \\
\text { July } 7 & -32.3 \\
\text { July } 21 & -33.0 \\
\text { Mean } & -30.2
\end{array}
$$

These numbers represent the mean of velocities found from two sets of measures separated in time by about a year. The agreement between the two sets is good, the greatest discrepancy being $6 \mathrm{~km}$. per sec., for the plate of July 4.

$$
\text { B.D. }+35.3953 \text {. }
$$

Plate 32A.- In the photographic region no bright lines or bright bands were observed, but there are absorption lines at $\lambda \lambda 4340.40(\mathrm{H} \gamma), 4471.43$ and 4120.84 -all very faint but fairly definite. Several other dark lines suspected. Velocity relative to Sun, derived from displacement of $\mathrm{H} \gamma,-8 \mathrm{~km}$. per sec.

$$
\text { B.D. }+36: 3956 \text {. }
$$

Plate 33A.-Plate underexposed. Very faint, fairly narrow band at $\lambda 4627.5$; bright band extending from $\lambda 4636.2$ to $\lambda 4670.0$.

Plate $39 \mathrm{H} .-$ Faint continuous spectrum to violet of $\lambda 4270$; faintly luminous band about $35 \mathrm{~A}$. U. wide with maximum intensity at $\lambda 4441$; fairly narrow band at $\lambda 4632.4$; bright band $\lambda 4634.3$ to $\lambda 4704.3$ with sudden drop in intensity at $\lambda 4669.59$, the redward end being fainter. Maximum of a faintly lumin- ous band at $\lambda 4785.2$. Narrow maxima suspected in brightest band.

$$
\text { B.D. }+35: 4013 \text {. }
$$

Plate 44B.-Band with maxima at $\lambda 4217.6$ and $\lambda 4233.2$. Middle of fairly bright band $1 / 4 \mathrm{~A}$. U. wide at $\lambda 4440.9$; maximum of faint band at $\lambda 4544.7$; very bright bands $\lambda 4637.9$ to $\lambda 4668.6$ and $\lambda 4677.45$ to $\lambda 4700.7$; very faint bands still farther redward.

$$
\text { B.D. }+36: 3987 \text {. }
$$

Plate 48B.-Fairly bright bands $\lambda 4050.6$ to $\lambda 4065.4$ and $\lambda 4081.8$ to $\lambda 4116.3$; faint bands $\lambda 4537.6$ to $\lambda 4553.7$ and $\lambda 4601.6$ to $\lambda 4655.1$; bright band $\lambda 4671.4$ to $\lambda 4701.5$.

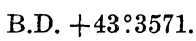

Plate 56A.-Dark $\mathrm{H} \gamma$; very bright band $\lambda 4617.2$ to $\lambda 4725.6$. This band shades gradually to red. Velocity relative to Sun, derived from displacement of $\mathrm{H} \gamma,-28 \mathrm{~km}$. per sec.

$$
\text { B.D. }+37: 3821 \text {. }
$$

Plate $47 \mathrm{C} .-$ Faint band $\lambda 4042.6$ to $\lambda 4069.8$; brighter band $\lambda 4081.2$ to $\lambda 4118.0$; faint band $\lambda 4187.5$ to $\lambda 4213.8$; brighter band $\lambda 4321.8$ to $\lambda 4358.2$; very faint band $\lambda 4364.8$ to $\lambda 4388.9$; bright band $\lambda 4481.2$ to $\lambda 4582.9$, with maximum at $\lambda 4544.3$; bright band $2 \lambda 4591.7$ to $\lambda 4660-1$, with minimum intensity at $\lambda 4607.9$; very bright band $\lambda 4660.0$ to $\lambda 4711.5$, being fainter from $\lambda 4843.8$ to $\lambda 4874.4$.

The wavelengths found above exhibit no notable departure from those of Dr. Campbell, given in the article referred to. The following lines and bands were found which are not mentioned in his article:

\begin{tabular}{lrl}
$\lambda$ of center & \multicolumn{1}{c}{ B.D. } & \multicolumn{1}{c}{ Description } \\
4120.84 & +35.3953 & Narrow dark line \\
4068.40 & 30.3639 & Narrow bright line \\
4630 & 36.3956 & Narrow faint band \\
4058 & 36.3987 & Fairly bright band 15 A. U. wide \\
4199 & 36.3987 & Fairly bright band 34 A. U. wide \\
4628 & 36.3987 & Faint band 54 A. U. wide \\
4056 & +37.3821 & Faint band
\end{tabular}

\section{J. C. Duncan.}

Astronomical LaboRatory,

HaRVARD UNIVERSITY, February, 1910.

2 This band has an appearance suggesting a number of dark lines crossing the band. 